\title{
Dietary saturated and omega-3 fatty acids affect growth and fatty acid profiles of Malaysian mahseer.
}

\begin{abstract}
The current study was conducted to determine optimal levels of dietary saturated fatty acids (SFA), n-3 PUFA and to study potential n-3 sparing effect of dietary SFA for Malaysian mahseer Tor tambroides. Juvenile T. tambroides were fed four trial diets with similar basal composition but different oil mixtures in a $2 \times 2$ factorial experimental design for 10 weeks. The two factors were the levels of dietary SFA and the levels of dietary n-3 PUFAs. Growth performance and fatty acid profile of tissues were analyzed at the end of the experiment. Significant differences in growth performance were observed among treatments, and fish fed the diet low in n-3 and high in SFA showed the best growth performance. T. tambroides fed the high $n-3$ diets showed a significantly higher $(\mathrm{p}<0.05)$ muscle total $n-3$ PUFA content compared to fish fed the low n-3 diets. The highest 22:6 n-3 and total n-3 PUFA content of the liver were also observed in fish fed the low n-3 and high SFA diet. However, the significant interaction $(\mathrm{p}<0.05)$ between dietary SFA and n-3 PUFA levels was observed for the total n-3 PUFA content of both muscle and liver tissues, suggesting an n-3 sparing action by dietary SFA. The results of this study suggest that $2.5 \% \mathrm{n}-3$ PUFA in the diet of T. tambroides, with an SFA to n-3 ratio of 15.3, is sufficient to provide the best growth performance and to retain the n-3 content of tissues.
\end{abstract}

Keyword: Saturated fatty acid; Polyunsaturated fatty acid; Mahseer; Growth; Tor tambroides. 